\title{
3D-QSAR reloaded: Open3DALIGN meets COSMOsar3D
}

\author{
Paolo Tosco ${ }^{1 *}$, Andreas Klamt ${ }^{2}$ \\ From 8th German Conference on Chemoinformatics: 26 CIC-Workshop \\ Goslar, Germany. 11-13 November 2012
}

A novel set of 3D descriptors, based on local grid-based COSMO $\sigma$-profiles (LSPs), has been recently proposed as a promising alternative to force-field based MIFs in 3DQSAR [1]. These descriptors are grounded in the quantum chemistry-based COSMO-RS theory, which has become one of the methods of choice for the prediction of fluid phase equilibrium constants (e.g., partition coefficients, solubilities, vapor pressures) in pharmaceutical chemistry and chemical engineering.

Herein we present two applications of COSMOsar3D to ligand-based and structure-based modeling. In the first case, we formulated a binding mode hypothesis for a

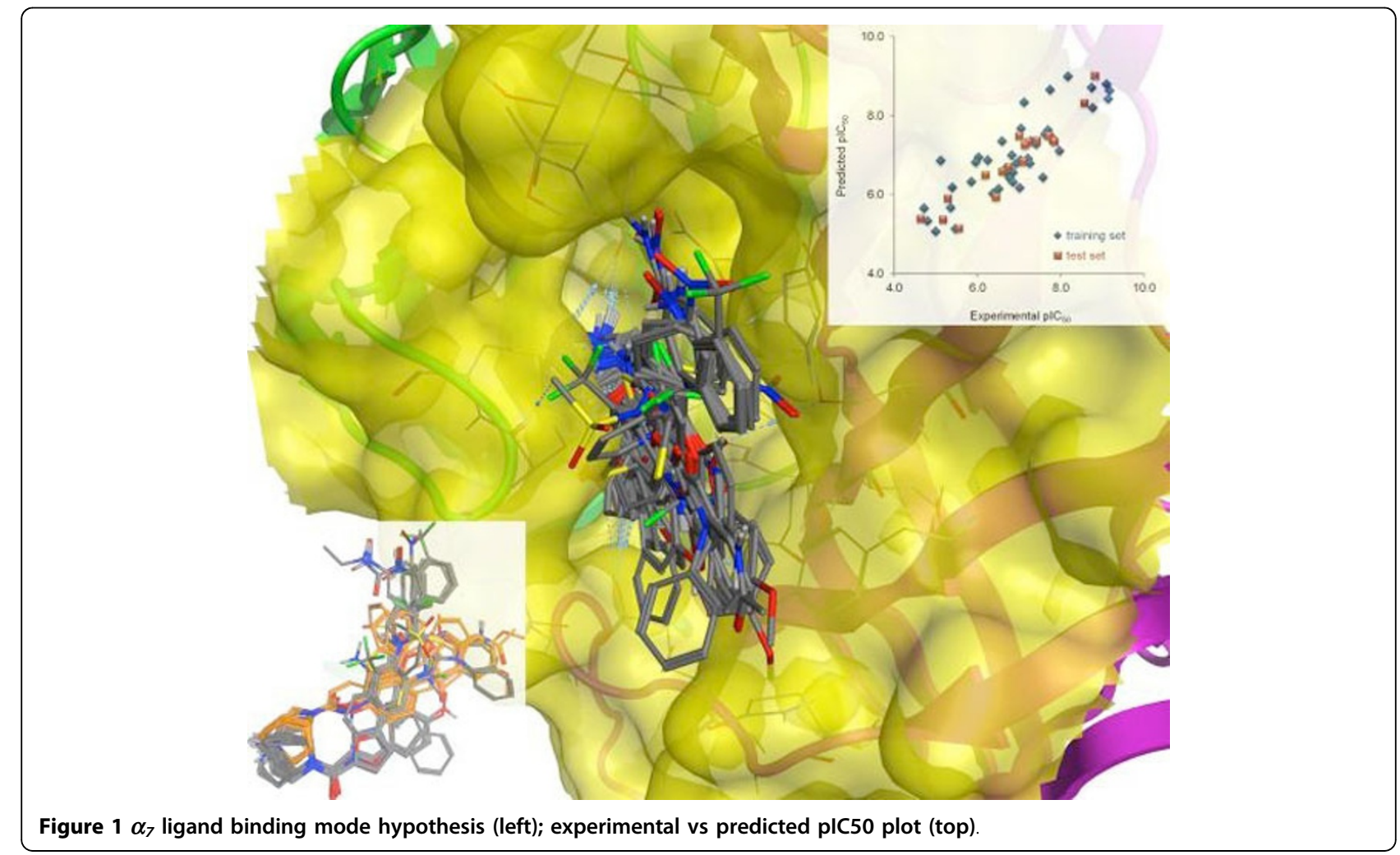

\footnotetext{
* Correspondence: paolo.tosco@unito.it

'Department of Drug Science and Technology, University of Turin,

Torino, 10125, Italy

Full list of author information is available at the end of the article
}

(C) Chemistry Central

(c) 2013 Tosco and Klamt; licensee BioMed Central Ltd. This is an Open Access article distributed under the terms of the Creative Commons Attribution License (http://creativecommons.org/licenses/by/2.0), which permits unrestricted use, distribution, and reproduction in any medium, provided the original work is properly cited. 

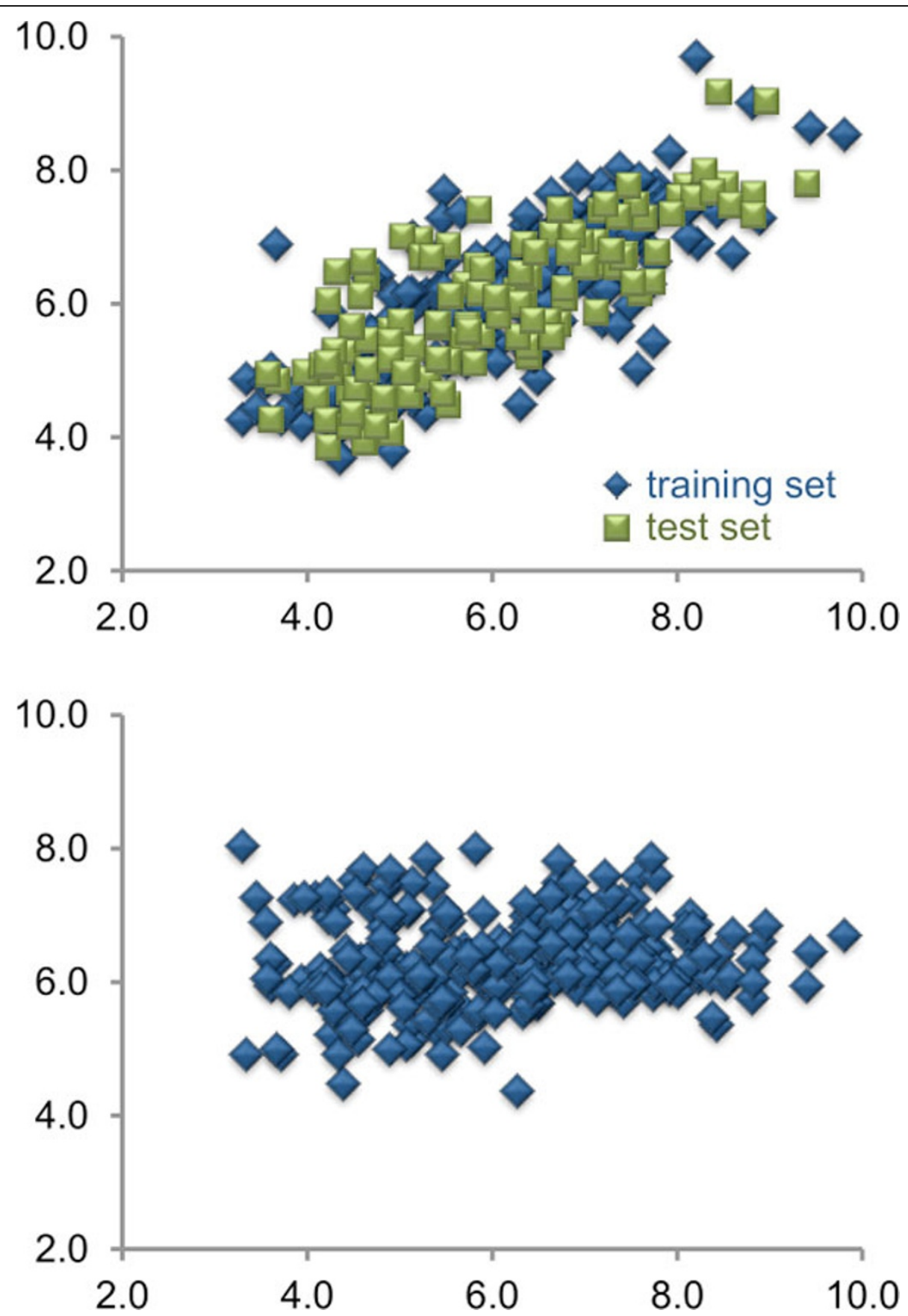

Figure 2 Comparison between the accuracy of pIC50 predictions made by COSMOsar3D (top) and AutoDock VINA (bottom).

series of 59 partial agonists at the human $\alpha_{7}$ nicotinic receptor using an iterative unsupervised alignment procedure implemented in Open3DALIGN [2]. Our hypothesis is compatible with site-directed mutagenesis data and fits an independent $\alpha_{7}$ receptor homology model; the associated COSMOsar3D model has excellent predictive power (Figure 1).

In the second case we used the Sutherland datasets to compare the accuracy of pIC50 predictions based on
AutoDock VINA scores to those based on COSMOsar3D models Open3DALIGN'ed on co-crystallized templates; in this context, COSMOsar3D predictions proved to be far more effective in ranking ligand potencies (Figure 2).

\section{Author details}

'Department of Drug Science and Technology, University of Turin, Torino, 10125, Italy. ${ }^{2}$ COSMOlogic GmbH and Co. KG, Leverkusen, 51381, Germany. 


\section{References}

1. Klamt A, Thormann M, Wichmann K, Tosco P: COSMOsar3D: Molecular Field Analysis based on local COSMO o-profiles. J Chem Inf Model 2012, 52:2157-2164.

2. Tosco P, Balle T, Shiri F: Open3DALIGN: an open-source software aimed at unsupervised ligand alignment. I Comput Aided Mol Des 2011, 25:777-783.

doi:10.1186/1758-2946-5-S1-013

Cite this article as: Tosco and Klamt: 3D-QSAR reloaded: Open3DALIGN meets COSMOsar3D. Journal of Cheminformatics 2013 5(Suppl 1):013.

\footnotetext{
Publish with ChemistryCentral and every scientist can read your work free of charge

"Open access provides opportunities to our colleagues in other parts of the globe, by allowing anyone to view the content free of charge." W. Jeffery Hurst, The Hershey Company.

- available free of charge to the entire scientific community

- peer reviewed and published immediately upon acceptance

- cited in PubMed and archived on PubMed Central

- yours - you keep the copyright

Submit your manuscript here:

http://www.chemistrycentral.com/manuscript/<smiles>c1ccccc1</smiles> 